\title{
TORSION OF THE OVARY IN CHILDHOOD
}

\author{
BY \\ SELWYN TAYLOR \\ From the Department of Surgery, Postgraduate Medical School of London, and the Belgrave Hospital for Children, \\ London
}

(RECEIVED FOR PUBLICATION JANUARY 17, 1952)

Torsion of the ovary is uncommon in childhood and usually occurs as a complication of ovarian tumour (Higgins, 1950). Such tumours are rare in this age group (Fraser, 1926) and it was previously thought that most of them were malignant (Lyttle, 1940). Lanman, writing in 1929, could report only five cases among 12,260 children seen in the surgical service of the Children's Hospital at Boston, Mass., and Wakeley in 1933 reported that not a single ovarian teratoma (the commonest ovarian tumour) had been seen during the previous 25 years at The Hospital for Sick Children, Great Ormond Street, London, and only one each at King's College Hospital, London, and the Belgrave Hospital for Children, London, during the same period. In recent years an increasing number of these tumours has been recorded and the total now stands at a little over 200 (Costin and Kennedy, 1948). The present report describes two further examples of this condition and draws attention to the fact that, as a result of a better understanding of the pathology, many previously designated carcinomas or sarcomas were probably dysgerminomas or granulosa cell tumours.

\section{Case Reports}

Case 1. A schoolgirl aged 10 years was admitted to hospital on March 18, 1950, with a one week's history of abdominal pain. The family and social history was irrelevant.

One week before admission the patient developed, across the lower abdomen, a continuous pain with occasional colicky attacks. She remained in bed for two days and vomited several times but was well enough to get up for the remainder of the week. The day before admission the pain was localized in the right iliac fossa but on the day of admission it extended across the whole of the lower abdomen and was increasing in severity. Immediately before arrival at hospital she vomited three times; her bowels were open normally. There had been no diarrhoea, micturition was normal and there was no recent history of a cold or cough.

On admission the temperature was $98 \cdot 6^{\circ} \mathrm{F}$., pulse 88 and respiration 24 . The child looked pale and ill. The general development, tongue, teeth and fauces appeared normal. Lymph nodes were palpable in the neck, axillae and groins.

There was tenderness and guarding in the right iliac fossa but no mass was palpable. Auscultation revealed normal bowel sounds. Per rectum a firm, smooth, tender mass was palpable in the pelvis. There was no vaginal discharge.

There were no other abnormal findings in the other systems. The urine was normal.

During the next 24 hours the pain persisted, the temperature remained normal but the pulse rate continued to rise. A provisional diagnosis of pelvic appendicitis or mesenteric adenitis was made and laparotomy was undertaken through a right lower paramedian incision.

There was a moderate amount of serosanguineous fluid in the peritoneal cavity. There was a tumour of the right ovary about 3 in. in diameter which, with the Fallopian tube, had undergone torsion and lay in the pouch of Douglas. The left tube and ovary appeared normal but the uterus was absent, its place being taken by a firm, fibrous cord about $\frac{1}{2} \mathrm{~cm}$. in diameter. No other abnormality was discovered in the abdomen. A right salpingo-oophorectomy and appendicectomy was carried out. The interior of the vagina appeared normal on inspection but the cervix was tiny.

Convalescence was uneventful, and the child left hospital on the ninth day.

In June, 1951, there was no evidence of a recurrence, the breasts were just developing and there was a trace of pubic hair; the child was fit and well. In December, 1951, the child was fit, well and developing normally. She was not yet menstruating.

Pathological RePort. Dr. J. K. Mason reported:

The 'cyst' was irregularly bossed and haemorrhagic in colour. It measured $75 \times 40 \times 60 \mathrm{~mm}$. On section it was seen to be a solid tumour with pale areas interspersed with large areas of haemorrhage. There was some attempt at lobulation visible. Between the tube and the ovary there was a small mass, size $27 \times 20 \times 15$ $\mathrm{mm}$. of different appearance from the tumour, which contained small cysts.

Sample sections taken through the main tumour mass all showed the same picture of large cells with heavily staining nuclei and abundant pale cytoplasm separated into lobules by fibrous stroma. Mitoses were fairly numerous. There was considerable lymphocytic infiltration of the stroma. Large areas of frank haemorrhage 
were present and the general structure was distorted by the changes following torsion. The appearances were those of an infarcted dysgerminoma of the ovary.

Section through the small mass below the tube showed a vascular structure almost completely replaced by

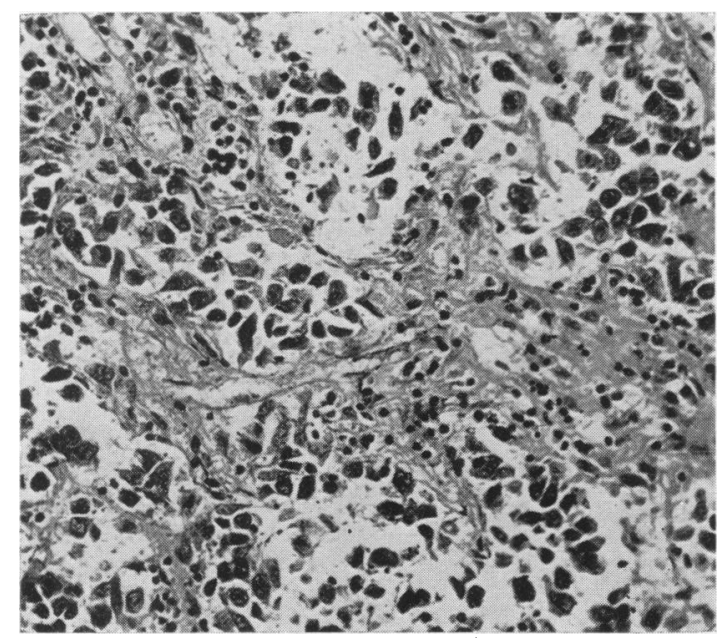

FIG. 1.-Photomicrograph of ovarian tumour removed from Case 1. The section shows fairly typical appearances of dysgerminoma $(\times 175)$.

haemorrhage. The appearance indicated that this was a mass of broad ligament tissues altered by torsion. The tube was filled with haemorrhage and the epithelium destroyed.

The appendix, which was $80 \mathrm{~mm}$. long and macroscopically normal, showed minimal haemorrhage in the submucosa and an exudate consisting of red cells and lymphocytes in the lumen. There was a small degree of early serosal inflammation.

Case 2. A schoolgirl aged 11 was admitted to hospital on May 5, 1950, with a three-day history of abdominal pain and vomiting.

For the first two days of the illness the child was constipated. On the third day she was still constipated and had left-sided abdominal pain. She was taken to another hospital where two enemas were administered and she was allowed to return home. On the fourth day she vomited twice. On the fifth day she was admitted to hospital; she vomited once.

On admission the temperature was $99 \cdot 4^{\circ} \mathrm{F}$., the pulse 104 and respiration 24 . The child was intelligent and co-operative. The face was flushed, the tongue furred and foetor of the breath was marked.

The abdomen was scaphoid and moved poorly. There was hyperaesthesia over the right lower quadrant and generalized tenderness to deep pressure, most marked in the right iliac fossa. Per rectum there was tenderness on the right side.

There were no other abnormal findings. The urine was normal.

There were 20,000 leucocytes per c.mm. (polymorphs $80 \%$, lymphocytes $10 \%$, monocytes $10 \%$ ).
A provisional diagnosis was made of an acutely inflamed appendix lying in the pelvis.

A lower right paramedian incision was made. There was no free fluid in the peritoneum. The omentum was normal, the appendix was exceptionally long but not inflamed and the small intestine showed no abnormality throughout its length. A mass was felt in the pouch of Douglas and on packing the intestines out of the way a pool of dark altered blood was seen. When this was mopped away, the mass was revealed as the left ovary and Fallopian tube, grossly oedematous and haemorrhagic. The ovary showed a small tear. The mass was
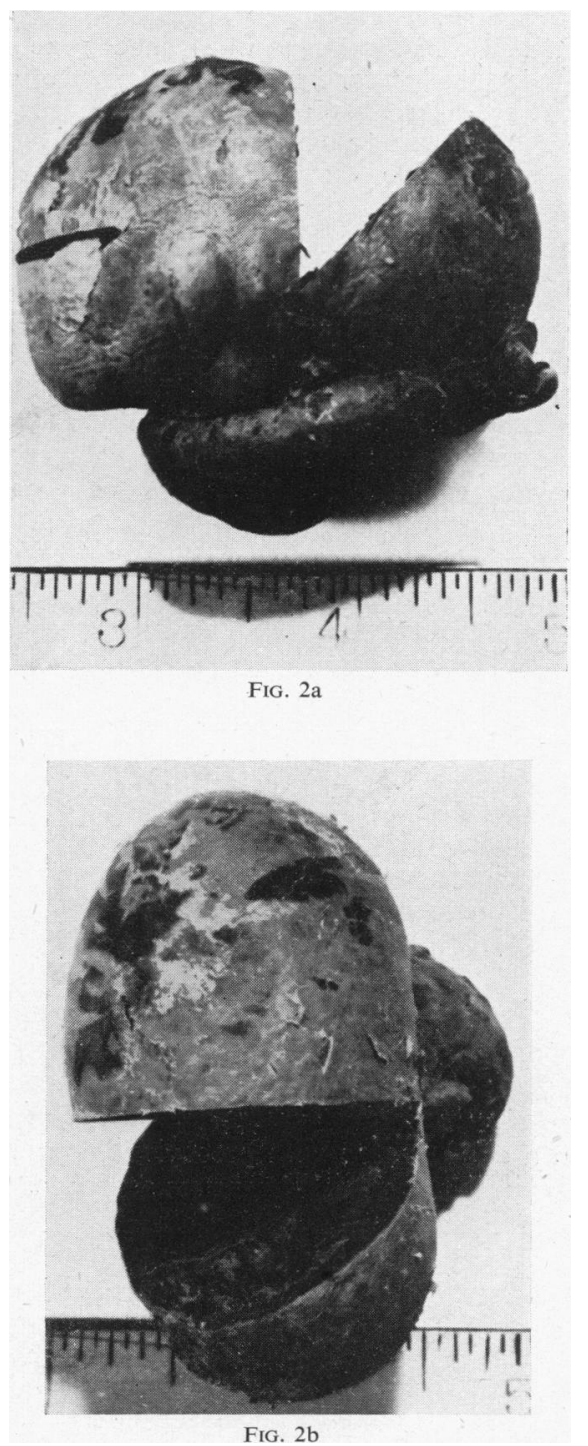

FIG. 2a and b.-Photographs of specimen removed from Case 2 . Note the complete infarction of the ovary. A wedge of tissue has been removed for section. (Scale in inches.) 
delivered into the wound and was found to have undergone torsion at the salpingo-uterine junction. The pedicle was clamped, ligatured and divided. The appendix was removed and the abdomen was closed in layers.

Immediately after operation the pulse rate was $\mathbf{1 5 0}$ but returned to within normal limits in 24 hours. Convalescence was uneventful and the child left hospital on the thirteenth day.

In December, 1951, the child was fit and well but not yet menstruating.

PATHOLOGY. Dr. J. D. Gray reported that blocks were made from different areas from a wedge cut from the ovarian tumour. The findings were the same in all sections.

A massive haemorrhage which had gone on to coagulation had torn its way through the ovarian architecture. There were not even cell islets or the remains of the stroma to be seen.

\section{Discussion}

Mayo and Butsch (1938) wrote: 'While comparatively rare, ovarian tumours occur with sufficient frequency among young girls to make it essential to keep the possibility in mind when dealing with abdominal symptoms', and then described the typical symptoms as being a mild, dull, recurrent pain with no nausea, vomiting or diarrhoea. In practice, however, the diagnosis is rarely made correctly except on those occasions when a tumour is palpable in the abdomen or pelvis.

The onset of torsion of an ovarian tumour almost always precipitates the signs and symptoms of an acute abdomen, although Lyttle (1940) reports the discovery at laparotomy of a benign ovarian cyst lying free in the peritoneal cavity of an infant of 2 months after spontaneous amputation of its pedicle at an unknown date. Torsion of a normal ovary appears to be excessively rare but has been reported by Fèvre (1949).

Simple cysts constitute $32 \%$ and dermoids, with which are included the teratomas, $24 \%$ of the ovarian tumours seen in infancy. The remaining $44 \%$ are made up of a variety of malignant or potentially malignant tumours: carcinomas, sarcomas, dysgerminomas and granulosa-cell tumours. When a child is seen with precocious development of the secondary sexual characters associated with a palpable mass in the pelvis, the diagnosis of granulosa-cell tumour of the ovary is almost certain.

Meyer (1931) was the first to describe the dysgerminoma, applying the name to solid carcinomatous ovarian tumours with a microscopic structure resembling that of seminoma of the testis and devoid of endocrine effects. These tumours are slower and less aggressive in growth (Willis, 1948) than testicular seminomas and they are sometimes cured by surgical removal. They do not appear to be very rare since by 1938 Novak and Gray were already able to collect 72 records and add a further 17 of their own. Three had occurred in children of 11 years or younger and attention was paid to their association with pseudohermaphroditism or sexual underdevelopment. There have been two reports of torsion of dysgerminoma in a child since 1938, by McNally (1945) and by Narat, Raider and Carton (1951). It is interesting that the child described (Case 1) should have no normal uterus although the vagina appeared to have developed adequately, and when she was seen recently she was apparently undergoing normal sexual development. Since the malignancy of this type of tumour is so variable, it was considered inadvisable to give deep $\mathrm{x}$-ray therapy, especially as this would have destroyed the remaining ovary.

It is only possible to conjecture the type of ovarian tumour which occurred in Case 2 since it had been disorganized by the torsion of its pedicle and only a mass of organizing blood clot remained. A somewhat similar state of affairs was described by Schaeffer and Cancelmo (1939) and the diagnosis was presumed to be a cavernous haemangioma of the ovary. A recent review of ovarian tumours in childHood (Dargeon, 1949) pointed out that well over half of them were not malignant and therefore the prognosis in Case 2 may prove to be a favourable one. The child has so far shown no evidence of malignant disease and is developing normally.

\section{Summary}

Two cases of torsion of the ovary in children are described, presenting with the signs and symptoms of an acute abdomen.

The incidence of these tumours in childhood is briefly reviewed.

The prognosis is discussed and is shown to be more favourable than was previously supposed.

I am most grateful to Mr. E. V. Willmott, F.I.B.P., F.R.P.S. for the photomicrograph and to Mr. H. Daverson for the photographs of the tumour.

REFERENCES

Costin. M. E. and Kennedy, R. L. J. (1948). Amer. J. Dis. Child., 76, 127.

Dargeon, H. W. (1949). Pediatrics, 3, 773.

Fèvre, M. (1949). Ombrédanne L. Précis Clinique et Opératoire de Chirurgie Infantile, 5th ed., rev. M. Fève. Paris.

Fraser, J. (1926). Surgery of Childhood. Vol. 2. London.

Higgins, T. T. (1950). Personal communication.

Lanman. T. H. (1929). New Engl. J. Med., 201, 555.

Lyttle, J. D. (1940). In Holt's Diseases of Infancy and Childhood, 11 th ed., p. 844 . New York.

McNally. P. A. (1945). J. Obstet. Gynaec. Brit. Emp., 52, 193.

Mayo, C. W. and Butsch, W. L. (1938). Minn. Med., 21, 256.

Meyer, R. (1931). Amer. J. Obstet. Gynec., 22, 697.

Narat, J. K., Raider, J. H. and Carton, A. K. (1951). Surgery, 30, 859 .

Novak. E. and Gray, L. A. (1938). Amer. J. Obstet. Gynec., 35, 925. Schaeffer, M. H. and Cancelmo, J. J. (1939). Ibid., 38, 722.

Wakeley, C. P. G. (1933). Surg. Gynec. Obstet, 56, 692.

Willis, R. A. (1948). Pathology of Tumours, p. 504. London. 